Volume 8

Issue 2 July

Article 4

July 1981

\title{
The Invisible Isolation of Deaf Women: Its Effect on Social Awareness
}

Gaylene Becker

University of California, San Francisco

Joanne Jauregui

Center for Independent Living, Berkeley, CA

Follow this and additional works at: https://scholarworks.wmich.edu/jssw

Part of the Social Work Commons, and the Speech Pathology and Audiology Commons

\section{Recommended Citation}

Becker, Gaylene and Jauregui, Joanne (1981) "The Invisible Isolation of Deaf Women: Its Effect on Social Awareness," The Journal of Sociology \& Social Welfare: Vol. 8 : Iss. 2 , Article 4.

Available at: https://scholarworks.wmich.edu/jssw/vol8/iss2/4 
THE INVISIBLE ISOLATION OF DEAF WOMEN: ITS EFFECT ON SOCIAL AWARENESS

\author{
Gaylene Becker, Ph.D. \\ Continuing Education Specialist \\ University of California San Francisco \\ and \\ Joanne Jauregui, B.A. \\ Coordinator, Department of Deaf Services \\ Center for Independent Living, Berkeley, CA
}

\begin{abstract}
The place of deaf women in relation to society is discussed, and the formative experiences that shape their personal development are described. Deaf women's needs are delineated, and suggestions are made for providers to meet these needs.
\end{abstract}

In recent years, women's place in society has come under close scrutiny. The attention brought to bear on stereotypes and attitudes about women, their roles, and their relationships has created a climate in which social change is beginning to occur. In contrast, deaf women remain almost untouched by these changes. The deaf community reflects the most traditional and conservative attitudes our society holds about women, attitudes that are perpetuated because deaf people are separated from the "hearing world" by the communication barrier created by deafness.

\title{
Methodology
}

The observations in this paper are based on the authors' experiences in the deaf community of the San Francisco Bay Area. Becker, a medical anthropologist, has conducted two one-year research projects on deaf persons. The first project, carried out with 200 deaf persons over the age of 60 , was concerned with the impact of lifelong deafness on old age. Data was gathered through daily participant-observation and through in-depth interviews with 60 persons. The second project was carried out with deaf persons between the ages of 20 and 60 and focused on adaptation to deafness over the life course, with particular 
attention to the development of coping behavior. In addition to extensive participant-observation in the deaf community, she carried out 40 in-depth interviews. She has also worked as a staff member and as a volunteer in various agencies that provide services to deaf people. Jauregui, an educator and social service provider, taught deaf children and adolescents in special education programs for 16 years before she began to work with adults. Since 1978 she has coordinated a project that provides services to deaf clients such as counseling, job development, the development of living skills, and advocacy. In response to the needs she observed among her clients, she has developed educational programs for low-functioning deaf persons, sex education programs open to the entire deaf community, and has sponsored a variety of consciousness-raising activities for deaf women. She is an active participant in many aspects of deaf community life and is herself deaf.

\section{Deafness: The Invisible Disability}

Emily Jones (pseudonym) screwed up her courage and walked through the senior center entrance. She was very lonely at home by herself and had been thinking of going to the Center for months. But it was a "hearing" agency, even though some of the staff knew sign language. She knew her visit might be a disaster. She dreaded making any mistakes. So she smiled warmly at the people at the front desk and walked quickly past them, not hearing them shout, "Come back and sign in," or seeing them shake their heads at each other. She walked on until she saw an approachable-looking man with a cane. He smiled at her. She took out a pad of paper and wrote "Deaf?" on it. The man started to nod and tell her something. She did not understand him. Like most deaf people, she could not read lips. He seemed to realize this because he pointed, then he motioned her to go with him. She followed him through several rooms to a door that said, "Deaf Program." People were standing inside signing to each other. The man walked into the room and drew their attention to himself. He pointed to Emily. They all moved toward her with arms outstretched, smiling and talking all at once. She was very relieved.

The initial experience Emily Jones had in this agency was off to a good start. Deaf and hearing staff members who understood the potential pitfalls of the hearing world and who could communicate with her in sign language were there to help overcome the barriers that exist for a deaf person in a world that can hear. But even in such a benign setting, there are pitfalls that expose the deaf person to mortification and embarrassment. 
Later on that day Emily was given a membership application to fill out. She worked on this form by herself for a long time, then reluctantly approached an interpreter. Pointing to the line that said, "Check one: _ Male _Female," she signed to the interpreter, "Me--which one?"

One of Emily's fears in going to this agency was realized. She was forced to display what she thought of as her "ignorance" and lack of education. She was not confused about her gender, but "girl" or "woman" were the only words she knew that described it.

Deafness is an invisible disability that only becomes apparent when the deaf person attempts to communicate. Deafness that occurs at birth or in the first years of life has a profound impact on the acquisition of language. Language acquisition occurs later than it does for children who can hear. Moreover, the majority of deaf children learn to communicate in American Sign Language, which differs grammatically and syntactically from English (Stokoe, 1960). This latter factor further impedes communication between the deaf and hearing worlds. Thus, deafness interferes with communication, in particular, with information and points of view of the hearing world that are conveyed in conversation and in the media, a major agent of social change. The linguistic/communicative gap that separates deaf people from the rest of society creates a cultural lag that is nowhere more apparent than in the place of deaf women in our society.

Deafness encompasses a range of social, emotional, and cultural experiences that are unique to persons who are deaf (Rainer et al. 1963). A profound hearing impairment early in life interferes with the socialization process. In all societies parents socialize their children by communicating cultural norms through language. Parents' behavior towards others is also an imortant factor in socializing children, since children overhear what their elders say to each other and combine these with their observations of adult behavior to develop norms for social behavior.

Deafness that occurs early in life interferes with the linguistic means of transmitting culture, and without language, the nuances of the socialization process are lost on deaf children. The great majority of deaf persons have hearing parents with whom they cannot communicate and whose value system differs in subtle but significant ways from their own. One hearing mother said of her adult deaf child, "You know, some of Betty's ideas come from that school she went to. They taught her to think different than if she had been brought up in the family. They took her [mind] away from me." Delayed language and socialization have tremendous significance for the problems deaf persons face in adulthood. 
Only 8 percent of deaf people have deaf parents (Schein and Delk 1974), and thus have a viable means of communicating with and learning from their parents through sign language. This small percentage of deaf people develop language skills at the same time as other developmental skills take place. At an early age they experiment with the language, as do children who can hear. They are a part of their parents' world, and they imitate, observe, and comprehend what is going on around them. In adulthood deaf persons who have deaf parents usually have a well developed ability to express and understand both their native language, American Sign Language, and signed English. Meadow (1968) has found that such children have a higher sense of selfesteem than children whose parents could hear. They were socialized primarily by their own parents and have a strong identification with deafness that carries them through life.

In contrast, most deaf persons did not begin to acquire language until they went to school at the age of five or six years. Entry into school was an emotional experience whether children were sent to state residential schools or to day schools. Suddenly, the child was put into the company of others with the same problem, and they began to learn the language together. Language acquisition and socialization thus took place concurrently for the majority of deaf children. Most deaf persons have stayed in school until they were 18 years old, spending 12 years in the institution. The recent pattern has been for children to board at school during the week and go home for the weekends, regardless of the proximity of their family homes. In the past, older persons usually spent the entire year at the institution, going home only in the summer. The separation of the child from the family has weakened the parent-child bond in many instances, a factor that places limits on deaf women's resources in adulthood.

Until recently, institutions for deaf children were highly segregated by gender, and as a result, girls spent considerable time together with with female teachers and counselors who instilled traditional American values about the role of deaf women in society. When deaf children were at home with their families, the inability to communicate with parents created strained relationships. The frequent complaint, by deaf women and men alike, that they were left out of conversation at the dinner table, symbolizes the status of the deaf person in the family as a "second class citizen."

During these formative years the peer group was formed, and the child learned to rely heavily on other children for emotional support and information about the world, a pattern that is maintained in adulthood. The social and emotional reliance on one's peers and the strong identification with other deaf persons that takes place in childhood combine to perpetuate the deaf community. 


\section{American Sign Language}

American Sign Language (ASL) is a visual language that is not based on English. As mentioned earlier, it has its own syntactical and grammatical structure (Stokoe 1960). For example, the question, "Have you finished eating?" would be signed "Finish eat?" in ASL with the accompaniment of appropriate body language. Few deaf people have language competency in both ASL and English.

ASL has its own set of at least 45 different handshapes--parallel to English's 26 alphabets. ASL also has a great variety of hand movements: slow, quick, long, short, repetitive. ASL is a standard sign language in the United States, but it has its own visual dialects depending on the part of the country in which it is being used. ASL users can readily tell where deaf people have come from or what schools they have attended in the past. ASL has its own inflections, all in facial expressions. Words for which there are no sign equivalents or for which signs are not known can be fingerspelled, using the manual alphabet. ASL is used by about 85 percent of the deaf population (cf. Wilbur, for a good discussion of ASL).

ASL has been called "the language of the outhouse" (Meadow 1972), since for many years sign language was forbidden, especially in classrooms. Children were forced to use the oral method to communicate with others. Children who used their hands to communicate were of ten punished by having their hands slapped (Higgins 1980). Sign language continued to be used, but in secret. The stigmatizing circumstances under which many deaf persons learned and began using sign language has had its impact on the language and on the level of linguistic sophistication of many sign language users. The signs themselves of ten tell a story about the frustrations of ineffective education. For example, one composite sign stands for "Too many big words." There are signs that indicate negative self-image, such as "dummy" and "pea-brain," and deaf people often apologize to hearing persons or to more highly educated deaf persons with comments such as "Me dummy--know nothing."

These negative feelings about self and about the language are countered by the tremendous symbolic signficance of the language. ASL is the symbolic badge of identity in the deaf community. Since many persons were "starved" for a means of communication in childhood before they learned sign language, there is immense pride in the language. Its resilience is a testimony to deaf perserverance. In groups of deaf people sign language becomes bigger and bolder than in public. Facial expression and body language take on new dimensions, and the richness of the language is exploited to its fullest. Such social events are the high points around which deaf social life pivots, and provide the nurturance to deal with the problems of everyday life. 


\section{Life in the Deaf Community}

Deaf persons tend to congregate in urban areas where the potential for finding $a j o b$ and for meeting other deaf people is greatest. The hub of the deaf community is the "deaf club," a term used by deaf persons themselves to describe one type of deaf organization that is scattered throughout most United States cities. The deaf club and its meaning for deaf people is so central to social life that a play entitled "Tales from a Deaf Club," has been written by two deaf playwrights. (For an excellent description of the deaf community, see Higgins 1980.)

The persons that emerged as leaders in the deaf community either had lost their hearing after they acquired language, or, as mentioned earlier, had deaf parents themselves. This small minority tended to excel academically, and frequently went on to college and professional careers while carrying out leadership roles in the deaf community. The acknowledged leaders were almost always men. Although there have been almost as many educated, professional women in the deaf community as men, female leaders have begun to receive acknowledgment of their leadership abilities only in the last few years. Nevertheless, change is slow to occur. For example, a recent women's meeting during a nationa1 convention attended by one of the authors was conducted by a man. The appropriateness of male leadership at a women's meeting was not questioned by the audience.

In contrast to the select few who became professionals, most prelingually deaf children had difficulty learning English and other academic subjects. They were prepared for sex-stereotyped careers. Boys were taught carpentry and printing, while girls were prepared to become seamstresses, homemakers, or keypunch operators. The focus on traditional activities began a pattern maintained at home by hearing parents because it required a minimum of communication. Inability to communicate between hearing parent and deaf child was thus a factor in reinforcing sex role stereotypes.

Parents of deaf daughters frequently neglect to prepare their daughter for coping with everyday life in adulthood. Becker (1980) found that the period of early adulthood was highly stressful because of this lack of preparation. Informants repeatedly said that they were ignorant of the ways of the world, that no one had explained what life outside the institution would be like. One exception to this pattern was a woman who stated that her mother had taught her everything she knew. Her mother even took her with her when she was planning her husband's funeral "because someday this will happen to you." She contrasted her own experience favorably with those of her friends, who were "lost" when they were first forced to handle such matters. 
Parents hoped that their daughters would eventually marry and that their husbands would take care of them. In fact, the majority of deaf women marry deaf men (Jacobs 1974), who of ten have been as poorly prepared for the roles and responsibilities of adulthood as their wives have been. As a result, deaf women frequently become the family managers, balancing their roles as wives, mothers, and full time workers while doing much of the family decision-making.

\section{Deaf Families}

Sandra Jackson sat on the faded couch in the sparsely furnished living room of her rented suburban house, and talked about her life. From the Midwest, she was born deaf and was sent to the state school for the deaf when she was five years old. After that, she only saw her family when she went home to the family farm for Christmas and summer vacations. They could not communicate with her. When she left school at 18 , she stayed in the city where she had gone to school and got a job in a factory. When some of her deaf friends decided to move to California, she came with them. Six months after she arrived, she met her husband, a printer, at a deaf club social. Shortly after they married she became pregnant and left the work force.

Sandra is now 37 years old and has four children between the ages of 8 and 15 . The oldest child, a girl, has been raised to be the family interpreter, since interpreting is viewed as an appropriate female role. She often interprets between her parents and the younger children who have never become proficient in sign language.

Three years ago Sandra went back to work over her husband's objections. "Boring sitting at home all day--cut off from the world. I felt very isolated."I

Sandra has had two jobs since she went back to work, first as a figure clerk in an insurance company, and more recently as an aide in an agency serving deaf people. Her current job has led her to reflect on the difficulties she experienced when she was a housewife. "I was ignorant of my rights. I thought of my inability to commicate with hearing people as my problem, not theirs. I didn't know what was going on in the world around me. There was nowhere to turn when I had a problem."

She is especially bitter about the impact of the communication barrier on her and her children. "I never had an interpreter when I went to the hospital for my children's births. The first time I was really scared... I didn't know what was

${ }^{1}$ All quotes have been translated into English. 
happening. No one told me what to expect. Later on, when the kids were getting older, I struggled with writing notes back and forth to the kids' doctors and school counselors. It was a waste of time. I never understood what people were trying to tell me. . . When a child was sick, I never knew just how serious it was, or what I could do if one of them was having trouble in school. I get angry just thinking about it." About work she says, "When I first went back to work, I would take the lowest pay--just grateful for a job. My husband kept saying, 'A woman's place is in the home,' but I was glad to get out and make $\$ 3$ an hour--and most deaf women are satisfied with that."

Sandra's husband still does not approve of her working, although the extra income is needed. In addition to her paycheck, she brings home too many new ideas. He complained in private, "She is always demanding an interpreter now when she has to go to school about the kids. She kept asking for a raise until she got one--and then she talked about it with her friends. It makes me look bad with the deaf--as if I can't take care of my family. Last week she even complained to a friend that I never babysat the kids when they were little." Sandra has not had contact with her own family since she left the Midwest almost 20 years ago. She relies on five or six deaf women friends for mutual support and companionship. She sees them often and shares with them the information she has access to in her new job. She is beginning to take on leadership activities in the deaf community, and sees herself as an advocate for deaf women and their needs. She is patient about her husband's attitude most of the time. She says, "It's hard on him being deaf. He's very cautious. He thinks deaf people are at the mercy of the hearing world, and that we have to be more careful than they [hearing people] do. He's afraid if we ask for anything, we will lose what we've got."

Like hearing women, the majority of deaf women eventually marry (71.5\% of deaf women marry by age 34 , Schein and De1k 1974). There is an increasing tendency for young deaf people to live together without getting legally married. While this practice reflects an increasing tendency in our society in general, it is also an outcome of the laws surrounding the Supplemental Social Security Income System (SSI). Many young deaf people who are untrained and unemployed qualify for SSI. If two persons who receive SSI marry, however, the amount they receive is reduced. Consequently, many young deaf people in their twenties and thirties remain legally unmarried so that they can continue to receive maximum benefits from SSI. The effect of this trend on family organization in the deaf community is as yet unknown. 
It is the cultural norm for deaf women to play a passive role and for deaf men to play a dominant role in the marital relationship, a model that is perpetuated by institutional socialization. In private these roles may be reversed, but in public individuals try to demonstrate culturally appropriate behavior that will maintain the status quo. This is one of many ways in which deaf persons try to normalize their behavior to their conception of "normative" American social behavior. Conformity to such a norm serves important functions, especially for those who must continually deal with their own nonconformity.

The majority of deaf couples have children who can hear. Only 9.1\% of deaf couples have deaf children (Schein and Delk 1974). Hearing children are used as interpreters, and parents also rely on them to explain customs, news, and other information gleaned from the hearing world. The oldest hearing daughter is usually given this responsibility, and sometimes even becomes an interpreter between the parents and younger children.

The manner in which deaf parents were socialized in school settings inevitably affects how they socialize their own children. Many deaf couples use rules of discipline from their own school experience for raising their children. Since these rules were established for handling large numbers of children, they are often overly rigid. Problems between parents and children may develop as a result.

A number of women find careers as teachers and counselors in schools for the deaf, and frequently remain single. Although marriage is highly valued in the deaf comnunity, a single person who works in an institutional setting becomes a part of the on-going social activities connected with the school. Since a continual round of social events is characteristic of these schools, the school becomes a substitute for one's own family. Single workers in the institution are not isolated from their peers as single deaf persons who work outside the system often are.

Women who deviate from these patterns in the deaf community are not easily accepted. Lesbians are frequently ostracized and often remain on the fringe of the community.

\section{Needs of Deaf Women}

As deaf women grow up, leave school, and begin to take on the roles of adult life, communication barriers continue to intervene in their adaptation. Despite the multiple roles that deaf women have traditionally carried out, they of ten manage without the emotional and social supports available to other women. Deaf women struggle to develop and maintain family cohesiveness without adequate preparation for marriage and motherhood, and their responsibilities in these roles. Nor are they prepared for the crises of family life, such as separation, divorce, or illness. 
Information about birth control, marital rights, child-rearing techniques and other practical aspects of marriage and family life is frequent1y lacking. Thus, lack of access to information that is disseminated to the public through the media severely restricts deaf women's options. Deaf women are not privy to information that has become commonplace to many American women because of the linguistic and communication differences that exist. These, in turn, affect deaf women's level of sophistication on various subjects. For example, the changing status of the birth control pill as a health risk is a subject that assumes considerable knowledge of health and health practices. The majority of deaf women have little information on such a topic. Instead, when a deaf woman wants information about a medication, she relies on her peer group. She may approach a person she considers knowledgeable, hold out the medication, and ask, "Is this all right for me to take?"

A1though there is no direct data on the subject, it is likely that because of the limited communication experienced between deaf women and their hearing families deaf women rely significantly less than hearing women do on their mothers and other relatives for information, help, and emotional support. The lack of role models and familial supports forces deaf women to turn to each other to meet their needs.

Early in life the deaf individual begins to develop a broad base of friendship in schoo1. This peer group forms the basis for social support that helps to sustain the individual amidst the ongoing difficulties of everyday life (Becker 1980). Bonds between women are particularly helpful in coping with everyday problems of living, as they give each other advice and share experiences.

Identification with the deaf community, begun in childhood, becomes an important part of the coping mechanisms that deaf women develop. This identification is reinforced by negative experiences in the hearing world that underline the difficulties of communication. As a result, deaf women have extremely restricted resources, usually limited to their peers and to the few agencies that serve the deaf community in any locale.

Lack of access to the media and other informational networks, poor English language skills, and distrust of the hearing world result in the use of social activities as opportunities to obtain and pass on information. Since the communication barrier is a deterrent to information retrieval, the information that does get through is often incorrect and is subject to further modification as it is passed from one person to the next. This situation is accentuated among deaf women who are members of ethnic minorities. They experience even greater problems in communication than other deaf women, and are particularly hesitant to seek out available resources. For example, one black woman came to an agency used by deaf people in an advanced state of pregancy because she had no financial resources to live on. When questioned about when she thought her baby was due, she said, "In about ten months." 
When we compare the deaf woman's access to resources with those of hearing women, it becomes apparent that the deaf woman is separated from services by the communication barrier imposed by the disability. This barrier places great limitations on the deaf woman by preventing her from obtaining knowledge that would help her to cope with the events of daily life as well as with life crises. There are two types of knowledge to which she has little access: 1) social knowledge, usually gleaned through informal conversations and overhearing other people talk; 2) formal knowledge from various media such as television, books, and magazines.

The lack of information has a dramatic effect on the quality of daily life for deaf people. What is more, change occurs slowly, of ten considerably behind the rest of society. The following example illustrates the extent of this informational vacuum. An 18-year-old woman showed up at an agency that serves deaf persons and confided to a staff member that she thought she was pregnant. In the course of the interview that followed, she was asked if she had even used birth control of any kind. Her response was, "What's that?"

\section{Recommendations for the Provision of Services}

The needs of deaf women are related to information and to access. Ways in which deaf women's needs may be met by providers fall into three categories: 1) educational programs such as workshops for deaf women of all ages; 2) visual information presented through the media; 3) access to health and social services. In all of these areas active participation of deaf women in planning and carrying out a program is a necessity to ensure success.

\section{Educational Programs for Deaf Women}

The structure of the deaf community lends itself to information dissemination through the workshop format. Information can be tailored for presentation to a group of deaf women and at the same time allow them to discuss new ideas with each other in privacy. The kinds of subjects appropriate to such a format include (but are not limited to): women's rights, health, job skills, development of leadership skills, marital relations, and parenting. Participation of deaf women in the presentation of material is optimum and will enhance learning.

Deaf women should also be encouraged to attend workshops developed for the general public. Before this goal becomes reality, however, the general knowledge of deaf women must approach that of their hearing contemporaries. In addition, certified sign language interpreters must be readily available. Deaf women should also be encouraged to keep up with the rapidly changing status of American women. 


\section{Visual Information through the Media}

In addition to programs that enhance and develop social and coping skills, deaf women need access to information of a didactic nature. For example, there is a growing movement in the United States to make television news programs accessible to deaf viewers through signs or captions. This effort has done much to keep deaf persons current with the state of the world around them.

Television and other visual media could also be used to provide education and to enlarge the linguistic abilities of deaf women. Programs designed specifically for deaf women could do much to increase the scope of information a deaf woman has at her disposal, for example, information about career options.

As an educational medium, television is probably the most effective tool in providing on-going education to deaf women. In contrast to the negative experiences many women had with formal education in school, television has the potential to develop ways of transmitting information to deaf women in new and exciting ways.

\section{Access to Health and Social Services}

Concurrent with an increase in the level of information available to deaf women is the need for services. As mentioned earlier, negative experiences in seeking services in the past have led deaf women to avoid "hearing" agencies. Providers who wish to make their services available to deaf women need to work with women in their local deaf community in planning, advertising, and delivering services.

Service delivery systems must make a concerted effort to inform deaf women about the services they offer. The importance of utilizing the informal grapevine of the deaf community to advertise programs cannot be too highly stressed, nor can the appearance of providers at deaf social events to advertise and informally discuss their programs. Staff members who are deaf and certified interpreters who are available at regular times ensure optimum participation of deaf consumers (Becker and Nadler 1980). Education aimed at staff members of facilities that intend to provide services and education is equally important so that staff will understand deaf culture and the special needs and concerns of deaf women.

Services to deaf women, particularly in specialized areas such as family planning services, should be undertaken by agencies serving the general public after conducting a needs assessment in the local deaf community. It is not possible nor is it desirable for agencies serving the deaf community exclusively to attempt to meet all the needs of deaf women. Indeed, the specialization of services inherent in complex, urban society presents a bewildering array to the deaf woman in search of solutions to problems she shares with all other women. Service 
delivery systems thus need to become aware of the deaf woman and her needs as a consumer and be able to respond appropriately to referrals, whether or not they routinely offer services to deaf women.

To summarize, the success of any new program for deaf women depends on inclusion of the following points:

1. The new program should be extensively advertised in the deaf community, using word-of-mouth, printed material, and personal appearances by providers and key deaf consumers at social events.

2. Use of certified sign language interpreters wherever appropriate. A rudimentary knowledge of sign language, e.g., knowing the signs for a few key words, helps to bridge the communication barrier, but the provider should not hesitate to use an interpreter after demonstrating an interest in sign language, so that communication will be clear. Certified sign language interpreters should be available at regular times, e.g., 9:00-12:00 Monday mornings, so that clients can plan accordingly.

3. Wherever possible, deaf personnel should be employed to work with other staff in providing services to deaf clients. Employment of deaf persons facilitates the acceptance of the program by deaf persons, enhances the education of staff, and normalizes the presence of deaf persons in the service delivery system.

4. Educate the hearing staff about the culture of deafness and ways of comunicating, utilizing deaf persons to provide the bulk of the information.

\section{Conclusion}

Deaf women in the deaf community are considered "second class citizens," based on the tendency of all deaf persons to imitate the values of the larger society. The conservatism of the deaf community in attempting to conform to cultural norms accentuates the culture lag that is related to the communication barrier.

Awareness of one's options and the ability to control one's life decreases the sense of frustration and powerlessness so frequently expressed by deaf women. As equal access to information and services takes place, the deaf woman's isolation will decrease and she will become more involved as a member of society. This involvement will not only affect her but her family, her friends, and her community as well. She will be able to better utilize the strengths of the deaf community when she has access to services. Ultimately, increased access will result in greater self-determination for all deaf women. 
Becker, Gaylene. 1980. Growing Old in Silence. Berkeley: University of California Press.

Becker, Gaylene and Gay Nadler. 1980. "The Aged Deaf: Integration of a Disabled Group into an Agency Serving Elderly People." Gerontologist 20:214-221.

Higgins, Paul. 1980. Outsiders in a Hearing World. Beverly Hills: Sage Publications.

Jacobs, Leo. 1974. A Deaf Man Speaks Out. Washington, D.C.: Gallaudet College Press.

Meadow, Kathryn P. 1968. "Parental Response to the Medical Ambiguities of Deafness." J. Health Social Behavior 9:299-309.

. 1972. "Sociolinguistics, Sign Language, and the Deaf Subculture." Pp. 19-33 in Psycholinguistics and Total Communication: The State of the Art ed. by Terry O'Rourke. Washington, D.C.: American Annals of the Deaf.

Rainer, John D., K. Altschuler, and F. J. Kallman. 1963. Family and Mental Health Problems in a Deaf Population. New York: Columbia University Press.

Schein, Jerome and Marcus T. Delk. 1974. The Deaf Population in the United States. Silver Spring, M.D.: National Association of the Deaf.

Stokoe, William C. 1960. Sign Language Structure: An Outline of the Visual Communication Systems of the American Deaf. Buffalo, N.Y.: Occasional Papers \#8, University of Buffalo.

Wilbur, Ronnie Bring. 1979. American Sign Language and Sign Systems. Baltimore: University Park Press. 